\title{
MOBILIZAÇÃO DO CONHECIMENTO CIENTÍFICO POR EGRESSOS DE UM MESTRADO EM ENFERMAGEM
}

\author{
Valéria Binato Santili DEPES ${ }^{a}$, Wilza Rocha PEREIRA ${ }^{b}$
}

\section{RESUMO}

Estudo que objetivou compreender como o processo de formação no Mestrado em Enfermagem contribuiu para mobilizar conhecimentos científicos em seus aspectos formais e políticos, pelos egressos atuantes em serviços de saúde. Pesquisa qualitativa exploratória, realizada na capital de Mato Grosso, em 2012. Os sujeitos foram nove egressos, mestres em enfermagem. Os dados foram coletados por entrevistas semiestruturadas e analisados por meio da técnica de análise de conteúdo temática e discutidos através do referencial teórico da Análise Institucional. Evidenciou-se o mestrado como dispositivo da instituição do conhecimento, sendo fortemente instituinte, por mobilizar no processo educativo, a qualidade política do conhecimento. Concluiu-se que os mestres enfermeiros, atuantes nos serviços de saúde, sentem-se melhor preparados para interferir e qualificar seus espaços de trabalho pelo manejo do conhecimento científico, político e ético, refinado e aprofundado ao longo da formação no mestrado.

Descritores: Enfermagem. Educação de pós-graduação em enfermagem. Pesquisa em enfermagem. Conhecimento.

\section{RESUMEN}

Estudio con el objetivo de comprender cómo el proceso de formación en la Maestría en Enfermería contribuyó a movilizar conocimientos científicos en sus aspectos formales y políticos, por los graduados que trabajan en los servicios de salud. Investigación cualitativa exploratoria, realizado en la capital de Mato Grosso, en el año 2012. Los sujetos fueron nueve graduados, magíster en enfermería. Datos fueron recolectados en entrevistas semiestructuradas y analizados por la técnica de análisis de contenido temático, y discutido a través del referencial teórico Análisis Institucional. Se encontró una maestría como elemento de la institución del conocimiento, siendo fuertemente instituyente, por movilizar en el proceso educativo, la calidad política del conocimiento. Se concluyó que los magísteres actuantes en los servicios de salud, se sienten más preparados y dispuestos a interferir y calificar en sus espacios de trabajo para la gestión del conocimiento científico, político y ético; refinado y profundizado durante su proceso formación en el Magíster.

Descriptores: Enfermería. Educación de postgrado en enfermería. Investigación en enfermería. Conocimiento. Título: Movilización del conocimiento científico por egresados de un máster en enfermería.

\section{ABSTRACT}

Study that aimed to understand how the process of training in the Masters of Nursing helped mobilizing scientific knowledge in terms of formal and political aspects, by graduates working in health services. Exploratory qualitative research, conducted at the state capital city of Mato Grosso, in 2012. The subjects were nine graduates, Masters in Nursing. Data were collected through semi-structured interviews, analyzed by using the technique of thematic content analysis, and discussed through the theoretical framework of Institutional Analysis. It was showed that the Masters was a device of the Institution knowledge, strongly instituting, by mobilizing in the educational process, the political quality of knowledge. It was concluded that the master's degree in nursing students who worked in health services, feel more prepared and ready to interfere and qualify their workspaces for the management of scientific, political and ethical knowledge; refined and deepened throughout the process of training in the Masters.

Descriptors: Nursing. Education, nursing, graduate. Nursing research. Knowledge.

Title: Mobilization of scientific knowledge by graduates of a nursing master's degree.

a Enfermeira da Escola de Saúde Pública do Estado de Mato Grosso. Mestre em Enfermagem pela Faculdade de Enfermagem da Universidade Federal de Mato Grosso (FAEN/UFMT). Membro do Grupo de Pesquisa Educação e Formação em Saúde e Enfermagem (GEFOR). Cuiabá, Mato Grosso, Brasil.

b Professora Associada III da FAEN/UFMT. Doutora em Enfermagem pela Escola de Enfermagem de Ribeirão Preto da Universidade de São Paulo (EERP/USP). Pós-doutorado em Educação pela Universidade Federal do Rio Grande do Sul (UFRGS). Líder do Grupo de Pesquisa GEFOR. Cuiabá, Mato Grosso, Brasil. 


\section{INTRODUÇÃO}

O estudo traz como tema a educação e a produção de conhecimentos em enfermagem em nível stricto sensu. Tratou-se da Enfermagem como ciência, trabalhando desde a perspectiva do corpo singular e específico de conhecimentos que esta vem construindo sobre o cuidado humano, que lhe aporta identidade e especificidade; e do espaço onde se educa e majoritariamente se produz esses conhecimentos no Brasil, a pós-graduação stricto sensu em enfermagem ${ }^{(1)}$.

Como ciência localizada na ampla área de conhecimento da saúde, a Enfermagem vem buscando sua legitimação nos campos científico e social. Estudos da área apontam, por um lado, que a pesquisa em enfermagem vem aumentando quantitativa e qualitativamente pelo país ${ }^{(1-2)}$; por outro lado, referem uma lacuna entre o conhecimento científico produzido na área e aplicação à prática profissional, de forma a demonstrar se e como vem ocorrendo essa utilização pelos que atuam no cuidado ou na gestão do cuidar em enfermagem ${ }^{(1,3-6)}$.

São estes supostos iniciais que levam a reflexão sobre quais conhecimentos são, de fato, necessários para melhorar as realidades que implicam o cuidar na enfermagem e advertem para a problematização da utilidade social do conhecimento de Enfermagem, de modo a transformá-lo em bem-estar das pessoas, grupos e coletividades ${ }^{(7)}$.

Considerou-se que o conhecimento científico tem uma face formal e uma face política ${ }^{(8)}$. A primeira, muito valorizada na graduação, caracteriza-se pelo domínio do saber instrumental e metódico. A segunda, que parece ser melhor enfocada na pós graduação stricto sensu, de nuances mais tênues e pouca visibilidade, trata da formação ética, relacionada à emancipação e autonomia dos sujeitos, capazes de definirem seu destino, ao mesmo tempo em que conseguem melhorar a vida dos demais sob seus cuidado ${ }^{(9)}$.

A expressão 'mobilização do conhecimento científico' é entendida como a capacidade dos egressos de colocar em movimento, de articular as faces formal e política, isto é, transformar o conhecimento disponível, advindo de leituras, de pesquisas científicas, em 'práticas'; aqui entendidas como o manejo da face política/ética do conhecimento científico, ou seja, um leque diferenciado de ações que inclui desde mudanças no discurso dos sujeitos, suas formas de inserção nos serviços, sua relação com a equipe de saúde e visão crítica que possam ter do processo de trabalho na enfermagem. $\mathrm{E}$ assim, contribuir para a qualificação da atenção à saúde dos usuários e fortalecimento da enfermagem como ciência.

Pressupõe-se que a realização do mestrado, pela oferta de experiências pedagógicas diversificadas, além da produção de conhecimento pela pesquisa, contribui no manejo do conhecimento científico. Ainda, traz ganhos adjacentes aos egressos, que incluem diferenciais qualitativos em relação ao processo de cuidar e de fazer a gestão da equipe de enfermagem e de saúde, ao proporcionar um ensino reflexivo quanto ao papel social do profissional, e trabalhar ampliando sua potencialidade como agente transformador do meio onde esteja inserido.

A partir desta problematização traçou-se como objetivo: Compreender como o processo de formação no Mestrado em Enfermagem vem contribuindo para a mobilização de conhecimentos científicos em seus aspectos formais e políticos, pelos egressos do curso que atuam em serviços de saúde na capital do Estado de Mato Grosso.

\section{METODOLOGIA}

Trata-se de uma pesquisa exploratória com abordagem qualitativa ${ }^{(10)}$, cujo cenário foi o curso de Mestrado da Faculdade de Enfermagem da Universidade Federal do Mato Grosso (FAEN/UFMT), situado em Cuiabá, capital do Estado. Criado em 2005, formou no período de 2006 a 2009, quarenta e três mestres em enfermagem. Foram doze egressos de mestrado que sustentaram sua dissertação de 2008 a 2011 e atenderam aos critérios de inclusão: ser egresso do mestrado; estar atualmente trabalhando na assistência no município de Cuiabá; exercer o cuidado relacional junto ao paciente ou trabalhar na gerência do cuidado e considerar a assistência o vínculo de maior ou igual relevância, caso atuasse também na docência ou outra área, ou atividade. Destes, nove aceitaram ser sujeitos desta pesquisa. -

Para coleta de dados utilizou-se entrevistas semiestruturadas; que foram gravadas e transcritas. Todos os sujeitos assinaram o Termo de Consentimento Livre e Esclarecido (TCLE); sendo a pesquisa matricial, da qual deriva este estudo, aprovada junto ao Comitê de Ética em Pesquisa do Hospital Universitário Julio Muller, sob o protocolo $n^{\circ}$ 798/CEP-HUJM/10. Os dados foram coletados nos meses de junho e julho de 2012 e as entrevistas, com duração média de 44 minutos, foram estruturadas a partir das seguintes perguntas: 
1) Como o mestrado em enfermagem contribuiu para a mobilização (produção, socialização, incorporação) do seu conhecimento científico sobre o cuidado produzido na área de enfermagem? 2) Como você vem utilizando o conhecimento científico sobre cuidado em enfermagem na sua atuação no cotidiano do trabalho de enfermagem?

Para fins de transcrição e preservação da identidade, os sujeitos foram identificados como (E1), significando entrevistado 1, (E2) entrevistado 2 e assim sucessivamente até (E9), como entrevistado 9.

Os dados coletados foram analisados pela técnica da análise de conteúdo modalidade temática ${ }^{(11)}$, e interpretados a partir do referencial teórico da Análise Institucional ${ }^{(12)}$. Esta teoria, escolhida por sua flexibilidade dialética, a qual será apresentada junto aos resultados e discussão, permite captar/ interpretar os movimentos dos sujeitos trabalhadores na constituição do seu objeto de trabalho e de si mesmos dentro do mundo do trabalho, considerando a diversidade do aprender, a pluralidade da vida e os valores em constante choque que conduzem às possibilidades de transformação social ${ }^{(12)}$.

No movimento inicial de organização dos dados, a pré-análise, realizada pela leitura vertical das transcrições, procurou-se, em cada entrevista, destacar os movimentos instituintes, forças produtivas/inovadoras, que tendem a fundar instituições ou transformá-las, e instituídos, conservadores/estabelecidos, que existem para ordenar as atividades sociais $^{(12)}$. Esta escolha, da leitura individualizada das falas, foi feita considerando os sujeitos em seus aspectos singulares, procurando evidenciar as particularidades de suas percepções.

Reordenou-se, então, o corpus pela identificação dos núcleos de sentido semelhantes, momento em que se realizaram as primeiras interpretações baseadas no referencial teórico. Assim, após analisados os diferentes núcleos de sentido, chegou-se a uma grande temática, denominada: $\mathrm{O}$ mestrado como dispositivo da instituição conhecimento.

\section{RESULTADOS E DISCUSSÃO}

\section{O mestrado como dispositivo da instituição conhecimento}

O termo instituição, para a teoria da Análise Institucional (AI), é um conceito essencial, definido como “[...] árvores de composições lógicas”(12) que, a depender de sua materialização e grau de formalização adotada, podem ser leis ou normas, se descritas, ou podem ser pautas, regularidades de comportamentos, quando não estão enunciadas de maneira manifesta ${ }^{(12)}$.

O conhecimento científico foi a instituição analisada neste estudo e ele se materializou dentro do processo de formação em nível stricto sensu, em um curso de mestrado. Como instituição, o conhecimento é regido por lógicas bastante formais e por normas bem conhecidas pelos pares, que a todo o momento sofrem reformulações, as quais interferem e produzem novos conhecimentos e novos métodos. Esta lógica exige atualização constante daqueles que atuam no campo científico, uma vez que um estudo que não siga corretamente um método, ou esteja em desacordo com a teoria que o embasou, corre o risco de ser rejeitado na área ao qual se destina. $\mathrm{Na}$ enfermagem, como nas demais ciências, o processo é similar, adquire-se legitimidade quando as regras e normas do campo do conhecimento são observadas.

O conhecimento científico, como todas as demais instituições, a saúde e educação entre essas, se compõe e se distingue pelas vertentes instituinte e instituída, uma não existindo sem a outra, uma em constante confronto dialético com a outra. Do lado instituinte da instituição conhecimento existem as forças produtivas como potências que tendem a “[ ...] operar mutações, transmutações" ${ }^{(12)}$ nas características do conhecimento, o que pode trazer o novo, funcionando como um processo criativo, visualizadas nos depoimentos:

Então hoje como eu relaciono isso com meu fazer [...] tentando trazer para o sujeito que eu atendo [...] um olhar mais ampliado, um cuidado que transcende aquele cuidado da enfermagem sobre o corpo, sobre o indivíduo, mas entendendo todo seu contexto social, emocional, trazendo a família para participar do processo. Dentro da própria gestão, quando eu proponho ações aqui dentro [...]. (E3)

[...] [o mestrado] foi importante de uma maneira geral... [...] as enfermeiras que a gente tem prestavam uma assistência pontual. [...] Hoje, não digo todos... [...] hoje a gente procura trabalhar... o que a gente faz com o pessoal aqui é o trabalho integral[ [...]. (E4)

As instituições, entidades abstratas na AI, para existirem, materializam-se em organizações, estas definidas como grandes ou pequenos conjuntos de formas materiais que efetivam as instituições ${ }^{(12)}$. 
As organizações dão vida às instituições e no caso da instituição conhecimento, a sua principal organização é a Universidade, que por sua vez se desdobra em unidades menores, denominadas estabelecimentos ${ }^{(12)}$.

O estabelecimento onde ocorreu este estudo foi a Faculdade de Enfermagem da Universidade Federal do Mato Grosso (FAEN/UFMT), que ao pensar em iniciar um mestrado acadêmico em enfermagem, realizou vários movimentos instituintes, internos e externos à organização da Universidade. Havia uma crença dentro do grupo, de que valia a pena o esforço, pois para sua legitimação no campo científico, como docentes pesquisadores, era preciso ter uma pós-graduação stricto sensu funcionando no local. Tal pós-graduação-considerou as particularidades regionais na produção científica advinda; além desse desejo estar em consonância com a política de expansão do V Plano Nacional de Pós-Graduação (PNPG).

Esse mestrado acadêmico proporcionou o manejo da face formal do conhecimento, traduzida pela teoria e instrumentalização dos sujeitos pela ciência, em um movimento dialético com sua face política, que se traduziu em ética, autonomia e emancipação. Ao provocar mudanças nos espaços de poder, os egressos fizeram surgir um processo instituinte, no qual novas formas de funcionamento estabeleceram novas relações entre os trabalhadores, e isto se fez a partir dos diversos conhecimentos adquiridos ao longo do curso de mestrado, como se constata no depoimento a seguir:

Dentro da minha dissertação, eu consegui convencer as pessoas que estão comigo aqui, de que a gente precisa mudar os modelos, e o ambulatório que antes era da medicina ele passa a ser um ambulatório de ensino, trazendo alunos de outras áreas da saúde [...] Isso [referindo-se ao mestrado] também me trouxe muita leitura $[\ldots ..] \mathrm{E}$ aí a gente acaba tendo argumentos científicos [...] dentro das leituras que eu realizei, [...]e da forma como eu demonstrei isso aqui dentro, [...] porque foi daí, depois que me colocaram na Coordenação no Ambulatório. (E3)

Para a manifestação do instituinte, a AI diz ser preciso existir dispositivos ou agenciamentos, entendidos como “[ [...] uma montagem ou artifício proposital/intencional produtora de inovações que gera acontecimentos"(12), faz surgir o desejo pelo novo, pelo que nos agrega, nos faz coletividade. Esta foi a perspectiva que se mostrou forte na pesquisa e nela o mestrado emergiu como um dispositivo, capaz de provocar a mobilização do conhecimento, tanto em seus aspectos formais, como nos políticos, pois os sujeitos do estudo revelaram os mais diversificados movimentos instituintes, que na compreensão deles foram processados durante a formação no mestrado.

A AI diz que os dispositivos como produtores de inovações, geram acontecimentos, cujo conceito é " $[\ldots]$ o ato, processo e resultado da atividade afirmativa do acaso. É o momento de aparição do novo, da diferença e da singularidade"(12). Ações que escapam das constrições do instituído, do organizado e do estabelecido.

Essa incorporação do conhecimento advindos do mestrado foi reconhecida como acontecimento, ou seja, as mudanças ocorridas nos sujeitos, os acasos que tocam os agentes e os tornam mais solidários e éticos, que tentam fazer a diferença na realização de suas ações como mestres enfermeiros nos micro espaços de atuação, visando alterações das práticas cotidianas, que não apenas o fazer pelo fazer:

[...] consegui trazer para dentro da instituição que eu já trabalhava desde a época que eu entrei no mestrado, um olhar diferente da enfermagem. [...] tive oportunidade de apresentar minha dissertação logo que eu terminei, numa mostra científica e os professores estavam presentes [...] então, quando a gente foi pensar no projeto político pedagógico da disciplina [...] a gente mudou muita coisa do que já vinha sendo discutido anteriormente”. (E3)

A produção de conhecimento em enfermagem é um fator de transformações na prática, pela maior visibilidade e reconhecimento das várias ações desenvolvidas pelos enfermeiros dentro do serviço. Destaca-se nesse processo a socialização da pesquisa, que agiu como um dispositivo, ao proporcionar mudanças no projeto pedagógico de determinada disciplina e o envolvimento de outros profissionais enfermeiros-docentes.

Outro egresso percebeu a realização de seu mestrado como um incentivo aos colegas enfermeiros do serviço onde atua para também realizarem a pós-graduação stricto sensu:

Eu percebi assim que... pelo menos quando eu fui fazer o mestrado, os meus colegas, os outros, nenhum fazia. Passaram-se quatro anos depois que eu terminei. Nossa! Tem um monte de colegas aqui que foram [...]. Então eu acho que isso faz diferença, a gente tenta trazer algo mais concreto, com comprovação científica para tudo que sabe. (E8) 
Tal fato é entendido como um dispositivo, ainda que não intencional, importante para a enfermagem enquanto ciência, que realiza práticas fundamentadas e necessita da pesquisa como instrumento para evolução do conhecimento científico, que a legitima e é a base do cuidado ${ }^{(7)}$.

Em suas singularidades, os sujeitos da pesquisa perceberam, de diferentes modos, as mudanças proporcionadas pelos conhecimentos científicos advindos do mestrado. Há aqueles que o perceberam como fonte de conhecimento, de aprofundamento teórico, embasamento daquilo que antes era percepção:

Acho que quando eu comecei... a conceituar, a entender mais as coisas... eu tinha muitas percepções, digamos assim, mas com muito pouca leitura. E no mestrado, uma das coisas que a gente faz muito é ler, ler, ler... mas lê coisa boa. Então a gente vai começando a entender o porquê que eu faço assim, [...]. (E5)

Com o mestrado você passa a ler muito, buscar muitas coisas e vê a evolução, porque você não fica tão restrita a um assunto, mas tenta a buscar de tudo, você está em contato com outras pessoas do meio científico, vai a congressos, [...] e a gente vê uma grande diferença no trabalho, parece que a mente amplia e muito. [...] Você passa a ter uma outra visão [...]. (E2)

Esses egressos desenvolveram um olhar ampliado após o mestrado, decorrente das leituras, pela incorporação do conhecimento científico e compreensão de que o conhecimento é o diferencial na realização das práticas, na contextualização e na reflexão sobre o próprio trabalho e seu produto, o cuidar. Tem-se o mestrado como dispositivo capaz de provocar, pelo conhecimento proporcionado, mudanças de postura em seus egressos, que por sua vez, poderão provocar transformações nas realidades dos serviços de saúde e de enfermagem pela mobilização do conhecimento científico.

Para além das mudanças profissionais, o conhecimento advindo do mestrado traz também mudanças pessoais para o sujeito:

Como ampliou... a gente sabe que assim... sempre tem que estar buscando mais, indo atrás, mas, deu uma grande diferença... Eu penso assim... eu antes do mestrado $e$ eu depois do mestrado.[...] Acho que o mestrado me proporcionou isso sim, esse crescimento profissional e pessoal, na minha vida por inteiro. (E2)
[...] isso influenciou a minha vida profissional, na minha vida pessoal... Eu falo isso bastante, eu acho que foi muito bom. [...]. (E8)

O conhecimento proporcionado pelo mestrado favoreceu a dimensão que compreende o conhecimento de si, de crença nas próprias potencialidades e de reconhecimento das limitações e formas de superá-las, proporcionando aumento da autoestima e autoconfiança ${ }^{(13)}$. É o lado instituinte da instituição conhecimento, que surge aos poucos durante estudos e reflexões realizadas ao longo do cursar o mestrado.

O mestrado, como dispositivo, traz a reafirmação do sujeito político/ético, enquanto profissional na sua realidade nos serviços de saúde, que consegue agora relacionar seu estudo no mestrado a um olhar mais solidário frente ao outro que é cuidado e que precisa de uma gestão do serviço com visão ampliada, de cuidado integral, de escuta atenta e consenso nas ações de enfermagem, como se vê nas narrativas:

[...] o que mais eu aplico é a questão do percurso que a pessoa percorre. [...] eu vejo a dificuldade, eu tento melhorar. O trajeto que ela percorre para conseguir esse cuidado. Pelo menos assim... conversar, orientar. Porque se a pessoa está orientada, vai facilitar para ela os caminhos a percorrer. (E9)

[...] um portador de diabete, de hipertensão [...] e ele acaba descompensando, a gente acaba descobrindo, nesse atendimento, algumas práticas populares, culturais que ele aprendeu com a família, na comunidade que ele mora. E aí a gente tenta, no transporte, fazer algumas orientações para isso. (E8)

A prática destes mestres enfermeiros, agentes para AI, está a serviço do organizante, como uma ação realizada que acaba por operar transformações da realidade ${ }^{(12)}$ ao ir além do atendimento à situação física do paciente, e se dispor a ouvir o outro, praticar a escuta, a alteridade, tentando compreender a cultura que cerca o adoecer do outro; a facilitar seu acesso aos serviços de saúde, atitudes que fogem da realidade vigente entre os profissionais.

Mas o conhecimento também tem o seu lado instituído que é o "[...] efeito final, esgotado da atividade instituinte" ${ }^{(12)}$, o resultado catalisado, o produto, revelando que as formas como o sujeito maneja o conhecimento dependem das suas maneiras de ver e compreender o mundo e se integrar nele. Há um único sujeito, dentre os nove que participaram da pesquisa, em quem foram encontradas 
marcas do instituído, ao deixar de reconhecer o processo de aprender diversificado do mestrado como um dispositivo instituinte; ao reiterar não haver ocorrido aprendizado significativo capaz de provocar mudanças nas maneiras de realizar suas práticas assistenciais, que agora se constituem no seu cotidiano de trabalho.

[...] quando você vai para o mestrado, você vai focar no seu trabalho [dissertação]. Tudo o que você vai buscar... Independente das disciplinas que vai ter que cumprir, é o seu trabalho. Então, se você está trabalhando com sistema de informação, tem que ir atrás só de sistema de informação, [...] não tem assistência no sistema de informação.[...] Então não deu, para ser específico, assim... não deu para eu interagir, para eu ter novos saberes, novos empoderamentos, vamos dizer assim... relacionado ao mestrado com a assistência. Não. (E1)

Percebeu-se que cada sujeito reagiu de uma forma muito particular ao processo de formação, confirmando que diferenças e singularidade marcam o aprender de cada sujeito, e que " $[. .$.$] o contexto$ do cuidado como o do processo educativo, pode funcionar como loci de consensos ou dissensos, de produção de autonomia ou de heteronomia, a depender dos potenciais desejantes dos diversos sujeitos que deles participam [...] não há serialização de reações, alguns sujeitos reagem com ações proativas e outros se recolhem e silenciam, outros ainda refletem e preparam-se para fugir ou enfrentar de forma intempestiva o acontecimento" ${ }^{\prime(9)}$.

Sob o olhar da AI, outro depoimento exemplifica, claramente, a força do conhecimento científico e a importância da pós-graduação para o desenvolvimento/efetivação da enfermagem como ciência e prática social por meio de seus enfermeiros:

[...] Eu estava tão técnica! Uma coisa que eu levava há anos! Desde 2000, sempre fazendo aquela rotina... e não me atentava para algumas coisas. [...] Então eu comecei a observar algumas coisas que antes [do mestrado] eu não me atentava... (E7)

Neste depoimento obteve-se que o conhecimento, proporcionado pelo mestrado, oportunizou uma nova perspectiva de ver os fatos e despertar para outros, que aqui foi chamado de olhar ampliado. Os agentes, pessoas protagonistas das práticas, ao adentrarem nas organizações, ainda com aspirações próprias, tendem a ser envolvidos nos processos de reprodução, reiterando o que já está posto, já existe, mantendo a função conservadora, cristalizada do organizado ${ }^{(12)}$.
O mestrado mostrou-se também, como um dispositivo de ressignificação desses sujeitos. Há mudanças nas formas de ser visto e também nas formas de ver-se e atuar, fazendo-o agora com mais segurança e poder de interferência. Mestres enfermeiros que fazem uso da qualidade política, adquirida na sua formação, ao tentarem romper as estruturas instituídas e mostrar aos gestores o olhar humanizado ao outro, solidário, de cuidado, como manifestam:

[...] Então nós tentamos, não foi só eu, é claro! É uma equipe. Nós fizemos uma proposta para que fosse atendido ele e a família com psicólogo, com nutricionista, mas realmente não compraram a ideia. (E7)

Eu sinto assim, quando eu saí eu estava no lugar correto. Se as coisas tivessem acontecido como deveria, eu teria conseguido fazer muito bem essa ponte. O mestrado me esclareceu muito, as leituras que foram feitas, o trajeto que eu fiz, de como deveria ser essa rede... os pontos que são frágeis no nosso Estado que precisariam ser trabalhados.(E6)

Reitera-se que o mestrado funcionou como um importante dispositivo, que provocou diversos e singulares movimentos na instituição conhecimento, pois chamou os sujeitos a moverem-se em outras direções que não as que estavam habituados. E, desta forma, realizarem os processos primeiros da AI, ou seja, a autoanálise, que permite aos sujeitos avaliarem as condições nas quais estão inseridos e buscarem soluções próprias para os problemas identificados; e a autogestão, que acontece concomitantemente à autoanálise, resultando em novas articulações na busca de melhoramentos nas práticas e na vida ${ }^{(12)} \mathrm{e}$ neste caso, do fortalecimento da ciência enfermagem.

\section{CONSIDERAÇÕES FINAIS}

$\mathrm{Na}$ realidade estudada encontrou-se aproximação entre a pós-graduação stricto sensu e a efetiva transformação nas maneiras de se manejar o conhecimento científico, possível de ser captada pela flexibilidade dialética da teoria escolhida, a Análise Institucional. Teoria que se mostrou capaz de dar significado aos achados de campo, e ajudou a interpretar as diferenças que marcam cada sujeito na tarefa de aprender e manejar o conhecimento proporcionado pelo mestrado.

O mestrado mostrou-se como um dispositivo que favoreceu o instituinte colocando em movimento 
a instituição conhecimento e proporcionando mudanças nas práticas dos egressos. A maioria dos sujeitos deixou claro que o mestrado os preparou e que hoje têm melhor percepção dos seus limites e possibilidades, ampliação na capacidade de argumentação, maior compreensão e reflexão sobre a profissão, pela institucionalização de atividades e pelo olhar ampliado ao outro que é cuidado. Sujeitos que acreditam fazer um melhor manejo político/ ético do conhecimento científico pelas estratégias de ensino, proporcionadas pelo mestrado, contribuindo no despertar de novos arranjos organizacionais, onde o conhecimento passa a ser o fundamento para propor alterações nas relações de trabalho e de cuidado e mesmo, na instituição conhecimento.

A pesquisa teve como limitação a aplicação de apenas uma técnica de coleta de dados. Este trabalho sugere a realização de estudos que capturem os movimentos instituintes efetuados pelos enfermeiros, especialistas, mestres ou doutores, no sentido de identificar possíveis transformações das práticas no cuidar, decorrentes da mobilização do conhecimento científico, que um olhar menos atento ou mais instituído não consegue captar.

\section{REFERÊNCIAS}

1 Alvim NAT. Produção e difusão do conhecimento científico da enfermagem na atualidade: desafios e implicações na formação e qualificação do enfermeiro. Esc Anna Nery Rev Enferm. 2010;14(1):07-09.

2 Paim L, Trentini M, Silva, DGV, Jochen, AA. Desafios à pesquisa em enfermagem. Esc Anna Nery Rev Enferm. 2010;14(2):386-90.

3 Cabral IE, Tyrrel MAR. Pesquisa em enfermagem nas Américas. Rev Bras Enferm [Internet]. 2010 [citado 2012 Mar 31];63(1):104-10. Disponível em: http:// www.scielo.br/pdf/reben/v63n1/v63n1a17.pdf.

4 Silva DMGV, Monticelli M, Brüggemann OM. Questões em debate na produção do conhecimento

\section{Endereço do autor / Dirección del autor / Author's address}

Valéria Binato Santili Depes

Rua Três, 615, Boa Esperança

78068-375, Cuiabá, MT

E-mail:valeria.b.s.d@hotmail.com

valeria.b.s.d@gmail.com em enfermagem. Texto \& Contexto Enferm. 2010;19(3):411-12.

5 Erdmann AL, Lanzoni GM. Características dos grupos de pesquisa da enfermagem brasileira certificados pelo CNPq de 2005 a 2007. Esc Anna Nery Rev Enferm. 2008;12(2):316-22.

6 Canever BP, Prado ML, Backes VMS, Gomes DC. Produção do conhecimento acerca da formação do enfermeiro na América Latina. Rev Gaucha Enferm [Internet]. 2012 [citado 2013 Fev 7];33(4):2 11-220. Disponível em: http://seer.ufrgs.br/RevistaGauchadeEnfermagem/article/view/25449/23973.

7 Cabral IE. As superações da Ciência de Enfermagem e os novos desafios. Rev Esc Enferm USP [Internet]. 2011 [citado 2012 Mar 31];45(3):551-52. Disponível em: http://www.scielo.br/pdf/reeusp/v45n3/ v45n3a01.pdf.

8 Demo P. Educação e conhecimento: relação necessária, insuficiente e controversa. $3^{\text {a }}$ ed. Petrópolis: Vozes; 2002.

9 Pereira WR. Entre a dominação simbólica e a emancipação política no ensino em enfermagem. Rev Esc Enferm USP. 201 1;45(4):981-88.

10 Depes VBS. A mobilização do conhecimento científico por egressos de um mestrado de enfermagem sob o olhar da Análise Institucional [dissertação]. Cuiabá (MT): Faculdade de Enfermagem, Universidade Federal de Mato Grosso; 2013.

11 Minayo MCS. O desafio do conhecimento: pesquisa qualitativa em saúde. $9^{\mathrm{a}}$ ed. revista e aprimorada. São Paulo: Hucitec; 2010.

12 Baremblitt GF. Compêndio de análise institucional e outras correntes: teoria e prática. $3^{\text {a }}$ ed. Rio de Janeiro: Rosa dos Tempos; 1996.

13 Waldow VR. Bases e princípios do conhecimento e da arte da enfermagem. Petrópolis: Vozes; 2008.

Recebido em: 11.03.2013

Aprovado em: 05.11.2013 